\title{
Влияние технологии двойного травления под затвор на параметры HEMT транзисторов на подложках GaAs и InP
}

\author{
(C) В.А. Беляков ${ }^{1}$, И.В. Макарцев ${ }^{1,2}$, А.Г. Фефрелов ${ }^{1}$, С.В. Оболенский ${ }^{1,2}$, А.П. Васильев ${ }^{3}$, \\ А.Г. Кузьменков ${ }^{3}$, М.М. Кулагина ${ }^{4}$, Н.А. Малеев ${ }^{4}$
}

${ }^{1}$ Акционерное общество Научно-производственное предприятие „Салют“, 603950 Нижний Новгород, Россия

${ }^{2}$ Нижегородский государственный университет им. Н.И. Лобачевского, 603022 Нижний Новгород, Россия

${ }^{3}$ Научно-технологический центр микроэлектроники и субмикронных гетероструктур Российской академии наук, 194021 Санкт-Петербург, Россия

${ }^{4}$ Физико-технический институт им. А.Ф. Иоффе Российской академии наук, 194021 Санкт-Петербург, Россия

E-mail: ilya0296@gmail.com; obolensk@rf.unn.ru

Поступила в Редакцию 12 апреля 2021 г.

В окончательной редакции 19 апреля 2021 г.

Принята к публикации 19 апреля 2021 г.

Разработаны транзисторы с высокой подвижностью электронов (НЕМТ) на основе гетероструктур InAlAs/InGaAs на подложке InP, обладающие удельной крутизной $\sim 1000$ мСм/мм, обратным напряжением пробоя > 10В и предельной частотой усиления транзисторов по току 140 ГГц. Также были разработаны HEMT транзисторы на основе гетероструктур AlGaAs/InGaAs/GaAs на подложке GaAs, выполненные по технологии двойной подзатворной канавки. Транзисторы демонстрируют максимальную измеренную удельную крутизну $520 \mathrm{MCм} / \mathrm{мм} \mathrm{и} \mathrm{пробивное} \mathrm{напряжение} \mathrm{затвор-сток} 14$ В. Предельная частота усиления транзисторов по току 120 ГГц. Благодаря увеличенному пробивному напряжению разработанные транзисторы были использованы в монолитных интегральных схемах усилителей мощности миллиметрового диапазона длин волн с выходной мощностью > 110 мВт.

Ключевые слова: транзистор, НЕMT, GaAs, InP, двойная канавка.

DOI: 10.21883/FTP.2021.10.51439.38

\section{1. Введение}

Интегральные схемы на основе полевых транзисторов широко распространены в системах связи, радиолокации, в космической аппаратуре. В последние годы большие усилия направлены на развитие устройств, работающих в Ка диапазоне, например, передатчиков и приемников систем космической связи [1]. Транзисторы с высокой подвижностью электронов (НЕМТ) на основе гетероструктур различного типа являются основными активными компонентами современной твердотельной СВЧ-электроники. В частности, на основе гетероструктур AlGaAs/InGaAs/GaAs были созданы высокочастотные усилители большой мощности, способные работать в миллиметровом диапазоне [2]. Тем не менее проблема создания усилителя с выходной мощностью > 110 мВт в диапазоне частот 90-110 ГГц до сих пор остается актуальной. В связи с этим необходимо создать транзистор, имеющий удельную крутизну вольт-амперной характеристики $(\mathrm{BAX})>500$ мСм/мм, удельный ток > 600 мА/мм, граничную частоту усиления по току $>110$ ГГц.

HEMT на основе гетероструктур InAlAs/InGaAs на подложках InP обладают рядом преимуществ перед теми, которые выполнены на подложке GaAs: более высокие рабочие частоты, минимальные шумы [2,3]. В [3] показано, что в случае уменьшения минимальной длины затвора до десятков нанометров и увеличения мольной доли индия в InGaAs канальном слое гетероструктуры возможно создание усилителей в диапазоне > 200 ГГц и даже продвижение в ТГц-диапазон частот. Однако недостатком HEMT на основе InP является более низкий уровень рабочего напряжения сток-исток (3-4B) и пробивного напряжения затвор-сток по сравнению с гетероструктурами на подложке GaAs [4], что ограничивает выходную мощность усилителей $\mathrm{W}$-диапазона частот на уровне нескольких десятков мВт. Однако в работе [5] удалось получить пробивное напряжение затвор-сток $\sim 10$ В. В свою очередь НЕМТ транзисторы на основе GaAs обладают более высокими рабочими напряжениями сток-исток и пробивными напряжениями, но они недостаточно эффективны на высоких частотах. Применение технологии травления двойной канавки под затвор транзистора на GaAs HEMT (DR-HEMT GaAs double-recessed-gate HEMT) позволяет улучшить частотную характеристику транзисторов и повысить плотность токов при сохранении и даже увеличении пробивного напряжения по сравнению с базовой технологией изготовления [5-9].

Цель данной работы - исследование влияния применения технологии двойного травления на характеристики НЕМТ транзисторов, выполненных на подложках GaAs и InP. Эффективность работы транзисторов про- 
верялась на монолитной интегральной схеме усилителя мощности в диапазоне частот 90-110ГГц с выходной мощностью > 110 мВт.

\section{2. Объекты исследования}

В работе были использованы приборные НЕМТгетероструктуры ES-228 и ES-344 с двухсторонним легированием канала (double HEMT), выращенные в АО НПП „Салют“ методом МОС-гидридной эпитаксии. Особенностями конструкции приборных double HEMTгетероструктур является наличие дополнительного поставщика электронов в канал - высоколегированного слоя $n^{+}$-AlGaAs, расположенного ниже канального слоя InGaAs, обеспечивающего поставку дополнительного количества электронов в проводящий канал [10], контактного слоя $n^{+}$-GaAs для формирования омических контактов и технологического стоп-слоя AlAs, предназначенного для создания равномерного углубления подзатворной канавки методом селективного химического травления [10]. Концентрация и подвижность 2D газа в канале составляет $3 \cdot 10^{12} \mathrm{~cm}^{-2}$ и $7000 \mathrm{~cm}^{2} /(\mathrm{B} \cdot \mathrm{c})$. Дизайн структуры показан в табл. 1.

Гетероструктура InAlAs/InGaAs (RC-1725) с двухсторонним легированием канала на подложке InP была выращена методом молекулярно-пучковой эпитаксии в ФТИ им. А.Ф. Иоффе, Санкт-Петербург [5]. Для используемой структуры типичные значения концентрации и подвижности 2D газа в канале составляют $(2.8-3.1) \cdot 10^{12} \mathrm{~cm}^{-2}$ и 9500-10000 $\mathrm{cm}^{2} /(\mathrm{B} \cdot \mathrm{c})$ соответственно. Дизайн структуры показан в табл. 2 [5].

В АО НПП „Салют“ были изготовлены три партии СВЧ полевых транзисторов с затвором длиной 100 нм и шириной 120 мкм: на структуре ES-228 травление проходило однократно, затвор расположен по центру

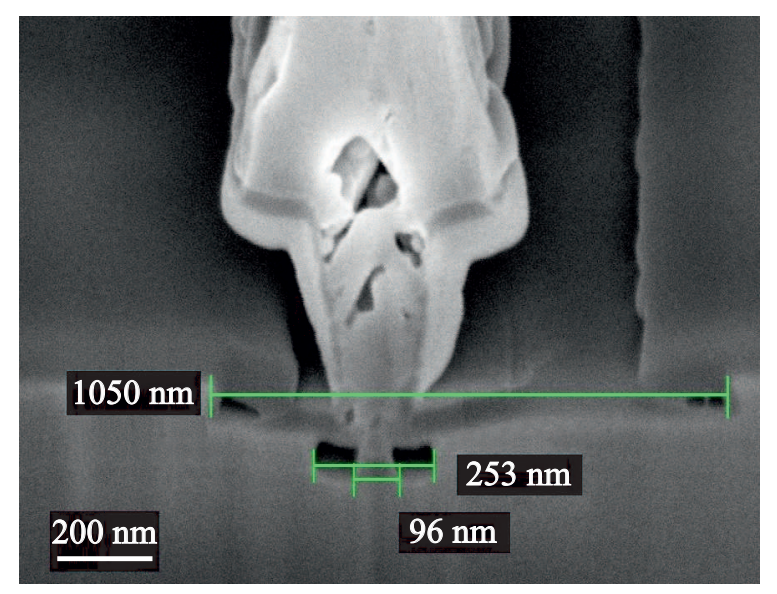

Рис. 1. Изображение поперечного среза затвора транзистора длиной 96 нм, полученное на растровом электронном микроскопе. Показана первая канавка длиной 1050 нм, вторая канавка длиной 253 нм.
Таблица 1. Параметры слоев транзисторной гетероструктуры HEMT GaAs

\begin{tabular}{l|c|c}
\hline \multicolumn{1}{c|}{ Наименование слоя } & Материал & $\begin{array}{c}\text { Толщина слоя, } \\
\text { эпитаксиальной структуры }\end{array}$ \\
\hline Контактный слой & $n^{+}-\mathrm{GaAs}$ & $50-60$ \\
Etch-stop слой & $\mathrm{AlAs}$ & $2-3$ \\
Барьерный слой 1 & $\mathrm{GaAs}$ & $15-20$ \\
Барьерный слой 2 & $\mathrm{Al}_{x} \mathrm{Ga}_{1-x} \mathrm{As}$ & $5-7$ \\
Легированный слой & $n^{+}-\mathrm{Al}_{x} \mathrm{Ga}_{1-x} \mathrm{As}$ & $15-20$ \\
Спейсер & $\mathrm{Al}_{x} \mathrm{Ga}_{1-x} \mathrm{As}$ & $2-3$ \\
Сглаживающий слой & $\mathrm{GaAs}$ & $1-3$ \\
Канальный слой & $\mathrm{In}_{x} \mathrm{Ga}_{1-x} \mathrm{As}$ & $8-15$ \\
Сглаживающий слой & $\mathrm{GaAs}_{\text {Сайсер }}$ & $1-3$ \\
Легированный слой & $\mathrm{Al}_{x} \mathrm{Ga}_{1-x} \mathrm{As}$ & $2-3$ \\
Буферный слой 1 & $n^{+}-\mathrm{Al}_{x} \mathrm{Ga}_{1-x} \mathrm{As}$ & $2-6$ \\
Буферный слой 2 & $\mathrm{Al}_{x} \mathrm{Ga}_{1-x} \mathrm{As}$ & $100-150$ \\
Подложка & $\mathrm{GaAs}$ & $200-300$ \\
& $i-\mathrm{GaAs}$ &
\end{tabular}

Таблица 2. Параметры слоев транзисторной гетероструктуры HEMT InP

\begin{tabular}{l|l|r}
\hline \multicolumn{1}{c|}{ Наименование слоя } & Материал & $\begin{array}{c}\text { Толщина слоя, } \\
\text { нм }\end{array}$ \\
\hline Котаксиальной структуры & & 20 \\
Еtch-stop & $\operatorname{In}_{0.53} \mathrm{Ga}_{0.47} \mathrm{As}$ & 3 \\
Контактный & $\mathrm{InAlAs}_{1}$ & 15 \\
Барьерный & $\operatorname{In}_{0.53} \mathrm{Ga}_{0.47} \mathrm{As}$ & 21 \\
Композитный канал & $\operatorname{In}_{0.52} \mathrm{Al}_{0.48} \mathrm{As}$ & 26 \\
Буферный & $\operatorname{In}_{0.52} \mathrm{Al}_{0.48} \mathrm{As}$ & 150 \\
Подложка InP (100) & &
\end{tabular}

между стоком и истоком (SR-HEMT GaAs), на структуpax ES-344 и RC-1725 проводилось двойное травление, затвор смещен к истоку транзистора (DR-HEMT GaAs и DR-HEMT InP соответственно). На рис. 1 показано изображение в растровом электронном микроскопе поперечного среза затвора транзистора, выполненного на подложке ES-344. Для других подложек форма затвора и длина были аналогичными.

Грибообразная форма затвора с высокой ножкой применяется для уменьшения паразитных емкостей транзистора, прежде всего емкости затвор-сток. Широкая шляпа необходима для уменьшения сопротивления затвора.

\section{3. Экспериментальные результаты}

\section{1. Измерение статических параметров транзисторов}

Во всех исследуемых партиях топология транзисторов имеет вид четырех параллельно включенных затворных секций длиной 30 мкм каждая (рис. 2). Истоки транзисторов соединены с помощью воздушного моста, 


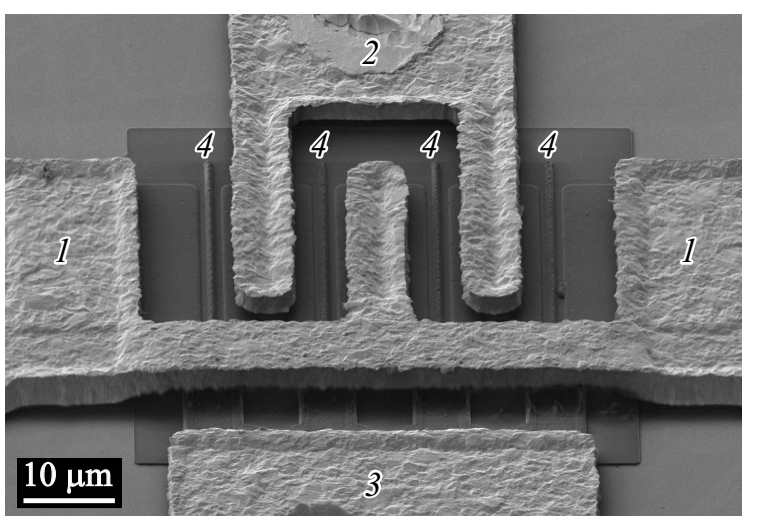

Pис. 2. Внешний вид транзистора с шириной затвора 120 мкм (4 пальца по 30 мкм): 1 - исток, 2 - сток, 3 - затворная шина, 4 - затворная секция.

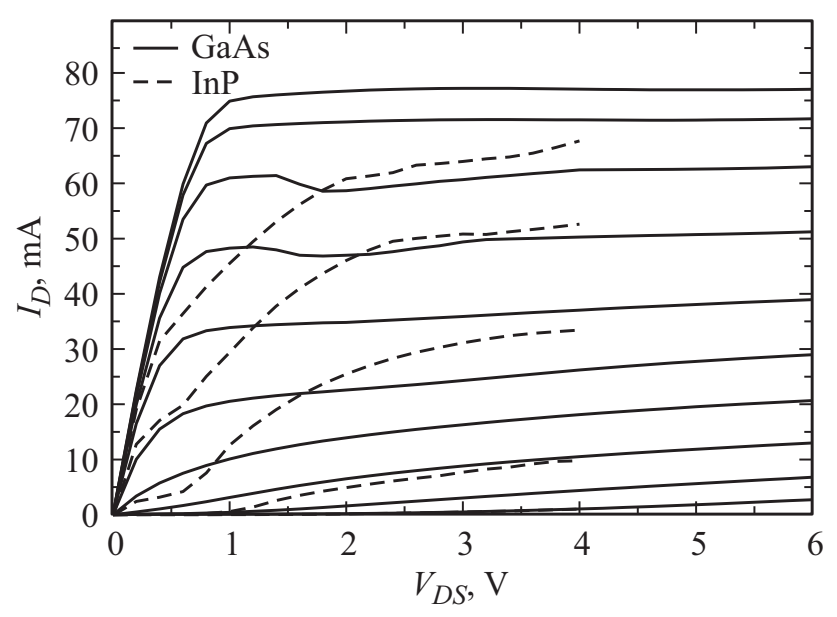

Рис. 3. Измеренные вольт-амперные характеристики DR-HEMT транзисторов, выполненные на подложках GaAs (сплошная линия снизу вверх) при изменении напряжения на затворе от -1.4 до $0.4 \mathrm{~B}$ с шагом $0.2 \mathrm{~B}$ и $\mathrm{InP}$ (штриховая линия снизу вверх) при изменении напряжения на затворе от -1 до -0.2 В с шагом $0.2 \mathrm{~B}$.

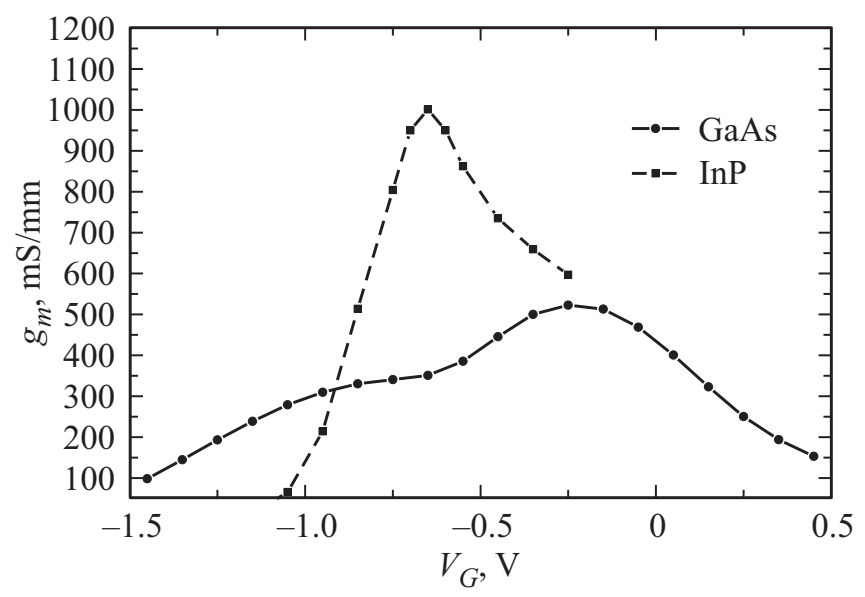

Рис. 4. Измеренные зависимости удельной крутизны изготовленных DR-HEMT на подложках различного типа от напряжения на затворе при напряжении на стоке 4B.
Таблица 3. Параметры транзисторов на постоянном токе

\begin{tabular}{l|c|c|c|c|c}
\hline \multicolumn{1}{c}{$\begin{array}{c}\text { Структура, } \\
\text { тип транзистора }\end{array}$} & $\begin{array}{c}V_{t h}, \\
\mathrm{~B}\end{array}$ & $\begin{array}{c}V_{b r}, \\
\mathrm{~B}\end{array}$ & $\begin{array}{c}g_{m}, \mathrm{MCM} / \mathrm{MM} \\
\left(V_{D S}=4 \mathrm{~B}\right)\end{array}$ & $\begin{array}{c}I_{D \text { sat }}, \\
\mathrm{MA} / \mathrm{Mm}\end{array}$ & $\begin{array}{c}V_{D S \max }, \\
\mathrm{B}\end{array}$ \\
\hline $\begin{array}{l}\text { ES-228 } \\
\text { SR-HEMT GaAs }\end{array}$ & 1.4 & 13 & 400 & 450 & $5-6$ \\
$\begin{array}{l}\text { ES-344 } \\
\text { DR-HEMT GaAs } \\
\text { RC-1725 } \\
\text { DR-HEMT InP }\end{array}$ & 1.3 & 14 & 520 & 670 & $7-8$ \\
& 12 & 1000 & 600 & $3-4$
\end{tabular}

который увеличивает емкости затвор-исток и затворсток на $2 \phi \Phi$.

Результаты измерений статических характеристик исследуемых транзисторов показаны на рис. 3. Наличие области отрицательного дифференциального сопротивления связано с междолинным рассеянием электронов в транзисторах с узким затвором. Двойная канавка увеличивает ток стока транзистора, что связано с увеличением скорости электронов в канале.

В табл. 3 представлены типичные значения напряжения отсечки $\left(V_{t h}\right)$, напряжения пробоя затвора $\left(V_{b r}\right)$ по уровню $1 \mathrm{MA} / \mathrm{MM}$, максимального рабочего напряжения сток-исток при максимальной крутизне $\left(V_{D S \max }\right)$, удельной максимальной крутизны $\left(g_{m}\right)$ и удельного тока насыщения стока $\left(I_{D \text { sat }}\right)$ SR-HEMT транзисторов (ES-228) и DR-HEMT транзисторов (ES-344) на подложках GaAs и для DR-HEMT транзисторов (RC-1725) на подложке InP.

Из таблицы следует, что транзисторы, выполненные по технологии двойного травления на подложке GaAs (ES-344), показали значительно лучшие параметры: крутизну BAX на 30\% больше, а удельный ток насыщения на 50\% больше, чем выполненные по технологии однократного травления.

Зарубежные аналоги DR-HEMT транзисторов демонстрируют удельную крутизну 500 мСм/мм, удельный ток насыщения 680 мА/мм [6].

Транзисторы, выполненные по технологии двойного травления на структуре InP HEMT, показали в 2 раза большую крутизну ( $1000 \mathrm{MCM} / \mathrm{MM})$, чем транзисторы на структуре ES-344 GaAs HEMT, вследствие большей подвижности электронов в канале и меньшего напряжения отсечки (см. рис. 4). Стоит отметить, что несмотря на большое пробивное напряжение затвор-исток (12 В), транзисторы на структуре InP имели рабочее напряжение на стоке не более $4 \mathrm{~B}$.

\section{2. Измерение СВЧ параметров транзисторов}

Малосигнальные высокочастотные S-параметры транзисторов были измерены с помощью векторного анализатора цепей в $\mathrm{W}$ диапазоне $(75-110$ ГГц). На рис. 5 показаны результаты измерений максимального стабильного усиления $G_{\max }$ изготовленных транзисторов, а 


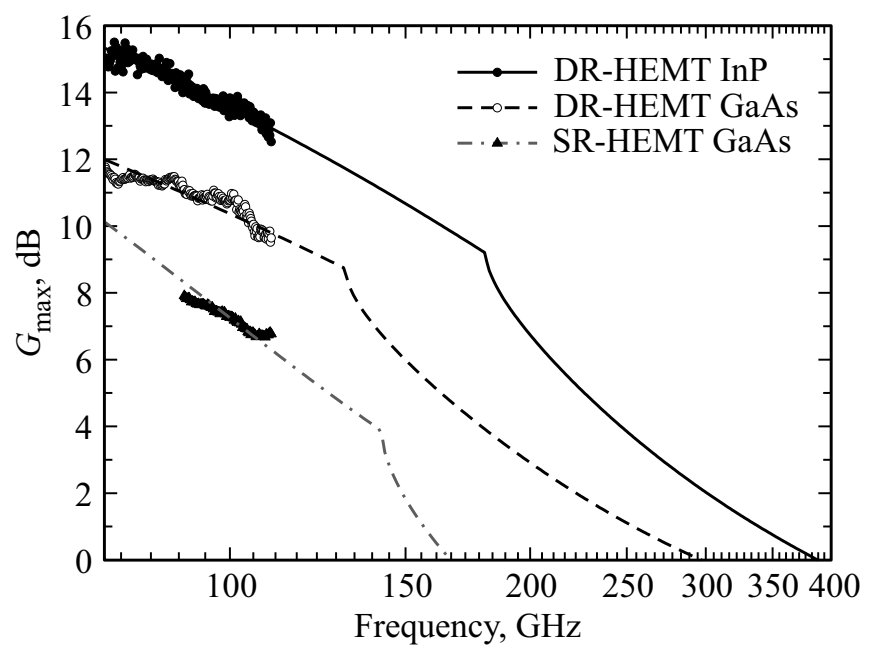

Pис. 5. Зависимости максимального стабильного усиления $G_{\max }$ от частоты для DR-HEMT InP, DR-HEMT GaAs и SR-HEMT GaAs. Точками показаны результаты измерений, линиями - результат моделирования.

также результаты моделирования S-параметров транзисторов (на рисунке показано сплошными линиями). Моделирование проводилось на основе малосигнальной эквивалентной схемы Поспешальского $[11,12]$. При этом предварительно учитывались внешние элементы цепи, необходимые для измерения параметров транзистора [13].

В табл. 4 приведены сводные параметры транзисторов: граничная частота $f_{t}$, предельная частота генерации $f_{\max }$, максимальное стабильное усиление $G_{\max }$ на частоте 100 ГГц.

Исследованные транзисторы DR-HEMT на подложке $\mathrm{GaAs}$ демонстрируют высокие СВЧ-характеристики в миллиметровом диапазоне. В частности, $G_{\max }$ на частоте 100 ГГц больше 10 дБ, граничная частота $f_{t}$ составляет 120 ГЦ (y SR-HEMT 108 ГГ). Таким образом, применение технологии двойного травления открывает перспективы использования рНЕМТ транзисторов на подложке $\mathrm{GaAs}$ для создания мощных усилителей в миллиметровом диапазоне.

Исходя из СВЧ измерений InP HEMT транзистора на частотах $\mathrm{W}$ диапазона, емкость обратной связи InP

Таблица 4. СВЧ параметры исследуемых транзисторов

\begin{tabular}{c|c|c|c}
\hline $\begin{array}{c}\text { Структура, } \\
\text { тип транзистора }\end{array}$ & $f_{t}$, ГГц & $f_{\max }$, ГГц & $\begin{array}{c}G_{\max }, \text { дБ } \\
(f=100 \text { ГГц })\end{array}$ \\
\hline $\begin{array}{c}\text { ES-228 } \\
\text { SR-HEMT GaAs } \\
\text { ES-344 }\end{array}$ & 108 & 167 & 7.3 \\
$\begin{array}{c}\text { DR-HEMT GaAs } \\
\text { RC-1725 } \\
\text { DR-HEMT InP }\end{array}$ & 120 & 298 & 10.8 \\
& 140 & 388 & 13.7
\end{tabular}

HEMT транзистора на 20\% меньше $(\sim 9 \phi \Phi)$, чем у GaAs HEMT (11 фФ), выполненных по технологии двойного травления. Граничная частота транзистора 140 ГГц.

На основе технологии двойной канавки в АО НПП „Салют“ был изготовлен усилитель с коэффициентом усиления > 13 дБ и насыщенной мощностью 140 мВт в диапазоне 90-96 ГГц.

\section{4. Заключение}

Технология двойного травления канавки под затвор позволяет улучшить параметры транзисторов, выполненных на основе гетероструктур $\mathrm{AlGaAs} / \mathrm{InGaAs} / \mathrm{GaAs}$ на подложке GaAs. Полученные значения тока насыщения $670 \mathrm{MA} / \mathrm{Mм}$, максимальной удельной крутизны 520 мСм/мм, граничной частоты 120 ГГц и максимального стабильного усиления $>10$ дБ позволяют применять транзистор при проектировании монолитных интегральных схем средней мощности $\mathrm{W}$ диапазона. При этом уровни пробивных напряжений затвора и максимального рабочего напряжения по стоку потенциально повышают надежность работы транзисторов при повышенных уровнях входного сигнала.

InP HEMT транзисторы предпочтительно использовать для создания малошумящих интегральных схем $\mathrm{W}$ диапазона частот благодаря сочетанию большей крутизны и меньшей емкости обратной связи в сравнении с GaAs HEMT. Для усилителей большой мощности данные транзисторы не подходят вследствие малого рабочего напряжения (3-4 B).

\section{Конфликт интересов}

Авторы заявляют, что у них нет конфликта интересов.

\section{Список литературы}

[1] J.S. Hong, M.J. Lancaster. IEEE Trans. Microwave Theory Techniques, 46 (1), 118 (1998).

[2] S.-J. Cho, C. Wang, R.K. Maharjan, N.-Y. Kim. Proceedings of APMC 2012 (Kaohsiung, Taiwan, 2012) p. 4.

[3] X.B. Mei, W. Yoshida, Z. Zhou, M. Lange, J. Lee, P.H. Liu, K. Leong, R. Lai, W.R. Deal. Extended Abstracts of the 2015 Int. Conf. on Solid State Devices and Materials (Sapporo, Japan, 2015) p. 1034.

[4] S. Hoshi, H. Moriguchi, M. Itoh, T. Ohshima, M. Tsunotani, T. Ichioka. Jpn. J. Appl. Phys., 42, 2367 (2003).

[5] Н.А. Малеев, А.П. Васильев, А.Г. Кузьменков, М.А. Бобров, М.М. Кулагина, С.И. Трошков, С.Н. Малеев, В.А. Беляков, Е.В. Петряков, Ю.П. Кудряшов, Е.Л. Фефелова, И.В. Макарцев, С.А. Блохин, Ф.А. Ахмедов, А.В. Егоров, А.В. Егоров, А.Г. Фефелов, В.М. Устинов. Письма ЖТФ, 45 (21), 29 (2019).

[6] S.-J. Cho, C. Wang, N.-Y. Kim. Microelectron. Eng., 113, 11 (2014). 
[7] Y.C. Chen, R. Lai, H. Wang, H.C. Yen, D. Streit, R.M. Dia, W. Jones, T. Block, P.H. Liu, T.-W. Huang, Y.C. Chou, K. Stamper. Int. Conf. on Indium Phosphide and Related Materials. IEEE, 509 (1997).

[8] Y. Zhong, X. Wang, Y. Su, Y. Cao, J. Zhi, Y. Zhang, X. Liu. J. Semicond., 33, 054007 (2012).

[9] L.F. Lester, P.M. Smith, P. Ho, P.C. Chao, R.C. Tiberio, K.H.G. Duh, E.D. Wolf. IEEE Technical Digest., Int. Electron Dev. Meeting (San Francisco, CA, USA, 1988) p. 172.

[10] J.B. Boos, W. Kruppa. Electron. Lett., 27, 1909 (1991).

[11] M.W. Pospieszalski. IEEE Trans. Microwave Theory Techniques, 37, 1340 (1989).

[12] G. Crupi, D. Schreurs. Academic Press, 467 (2014).

[13] M. Koolen, J. Geelen, M. Versleijen. IEEE Bipolar Circuits Technology Meeting, 189 (1991).

Редактор Г.А. Оганесян

\section{Effect of double recess technology on the parameters of HEMT transistors on GaAs and InP substrates}

V.A. Belyakov', I.V. Makartsev',2, A.G. Fefelov', S.V. Obolensky ${ }^{1,2}$, A.P. Vasilyev ${ }^{3}$, A.G. Kyzmenkov ${ }^{3}$, M.M. Kulagina ${ }^{4}$, N.A. Maleev ${ }^{4}$

1 JSC SPE „Salyut", 603950 Nizhny Novgorod, Russia

${ }^{2}$ Lobachevsky State University of Nizhny Novgorod, 603022 Nizhny Novgorod, Russia

${ }^{3}$ Submicron Heterostructures for Microelectronics,

Research \& Engineering Center,

Russian Academy of Sciences,

194021 St. Petersburg, Russia

${ }^{4}$ loffe Institute,

194021 St. Petersburg, Russia

Abstract High electron mobility transistors (HEMTs) have been developed based on InAlAs/InGaAs heterostructures on an InP substrate, with a transconductance of about $1000 \mathrm{mS} / \mathrm{mm}$, a reverse breakdown voltage of more than $10 \mathrm{~V}$ and a unity-gain cutoff frequency is $140 \mathrm{GHz}$. In addition, HEMT transistors based on $\mathrm{AlGaAs} / \mathrm{InGaAs} / \mathrm{GaAs}$ heterostructures on a $\mathrm{GaAs}$ substrate with double gate recessing technology have been developed. This transistors demonstrate a maximum measured transconductance of the current-voltage characteristic of $520 \mathrm{mS} / \mathrm{mm}$, a maximum drain current of $670 \mathrm{~mA} / \mathrm{mm}$, and a gate-drain breakdown voltage of $14 \mathrm{~V}$ and a unity-gain cut-off frequency is $120 \mathrm{GHz}$. Due to the increased breakdown voltage, the developed transistors have been used in monolithic integrated circuits of millimeter-wave power amplifiers with an output power of more than $110 \mathrm{~mW}$. 